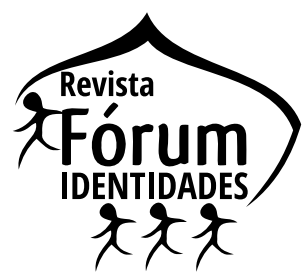

\title{
AMEFRICANIDADES: MEMÓRIAS E ESCRITAS DE MULHERES NEGRAS 1
}

\author{
AMEFRICANITIES: \\ MEMORIES AND WRITINGS OF BLACK WOMEN
}

\author{
Júlia Dias da Silva²
}

\begin{abstract}
Resumo: Esta escrita pretende articular memória e história, destacar a produção literária de mulheres afrodiaspóricas e ressaltar a figura da mulher negra que, enquanto sujeito e protagonista de sua trajetória, reconstrói e subverte discursos branco-hegemônicos. Trata-se de relacionar narrativas de passado e de presente, a partir da leitura de Um defeito de cor, de Ana Maria Gonçalves, e Jonatás y Manuela, de Luz Argentina Chiriboga. Cab ressaltar que as personagens destas obras podem ser lidas como personificações da encruzilhada de vivências e dos trânsitos que são causa e consequência de ser mulher negra nas Américas.
\end{abstract}

Palavras-chave: Amefricanidade. Escrita de mulheres negras. Pensamento afrodiaspórico. Um defeito de cor, Jonatás y Manuela.

\begin{abstract}
This writing aims to articulate memory and history, highlight the literary production of Afro-diasporic women and highlight the figure of the black woman who, as the subject and protagonist of her costume, reconstructs and sustains white-hegemonic discourses. It seeks to relate narratives of the past and present, based on the reading of Um defeito de cor, by Ana Maria Gonçalves, and Jonatás and Manuela, by Luz Argentina Chiriboga. It should be noted that the characters in these works can be read as personifications of crossing houses and two transits that are cause and consequence of being a black woman in the Americas.
\end{abstract}

Keywords: Amefricanity. Black women's writing. Aphrodiaspora thought. Um defeito de cor, Jonatás y Manuela.

\footnotetext{
${ }^{1}$ Artigo recebido em 14 de agosto de 2021 e aceito para publicação em 30 de setembro de 2021.

2 Doutoranda e Mestra em Literatura e Cultura (UFBA); Especialista em Literatura Brasileira (UFRGS); Especialista em Gramática e Ensino de Língua Portuguesa (UFRGS); Graduada em Letras (PUCRS); Bolsista Fapesb. Membra do grupo de pesquisa Yorubantu. ORCID: https://orcid.org/0000-0003-3325-1706 e-mail: julia.ddias@gmail.com.
} 
ROTUNDAMENTE NEGRA

Mi niego rotundamente a negar mi voz mi voz mi sangre y mi piel y my niego rotundamente a dejar de ser yo

a dejar de sentirme bien cuando miro mi rostro en el espejo com mi boca rotundamente grande y mi nariz rotundamente hermosa $y$ mis dientes rotundamente blancos y mi piel valientemente negra y me niego categóricamente a dejar de hablar mi lengua; mi acento y mi historia y me niego absolutamente a ser de los que se callan de los temen de los que lloran, porque me acepto rotundamente libre rotundamente negra rotundamente hermosa.

- Shirley Campbell Barr

Neste estudo, intento analisar as memórias e as escritas amefricanas de mulheres negras, aqui representadas por Ana Maria Gonçalves e Luz Argentina Chiriboga, a partir de recortes de duas obras produzidas no Brasil e no Equador, respectivamente. Estas são contadoras de histórias ancestrais e que reconfiguram, por meio da artesania de suas palavras, olhares e saberes sobre as identidades e culturas afroamericanas.

A leitura das obras aqui apresentadas está embasada, sobretudo, no conceito de Amefricanidade da filósofa e antropóloga brasileira Lélia Gonzalez. Este aporte teórico refere-se às experiências partilhadas entre mulheres negras e homens negros em diáspora e entre mulheres e homens indígenas contra a dominação colonial na América Latina. Assim, a Amefricanidade:

Resgata uma unidade específica, historicamente forjada no interior de diferentes sociedades que se formam numa determinada parte do mundo. Portanto, a Améfrica, enquanto sistema etno-geográfico de referência, é uma criação nossa e de nossos antepassados no continente em que vivemos, inspirados em modelos africanos. Por conseguinte, o termo amefricanas/amefricanos designa toda uma descendência: não só a dos africanos trazidos pelo tráfico negreiro, como a daqueles que chegaram à América muito antes de Colombo (GONZALEZ, 1988, p. 77). 
Embora sejam consideráveis as diferenças entre Brasil e Equador, países atravessados por questões socioculturais distintas, Gonçalves e Chiriboga narram histórias comuns à escravização e às consequências da colonização que perduram até hoje nas Américas. Para além das fronteiras, negras e negros tiveram experiências coletivas de discriminação, subordinação e estigmas (BARR, 2017). Esta discussão justifica-se a partir do que afirma Gonzalez:

Embora pertençamos a diferentes sociedades do continente, sabemos que o sistema de dominação é o mesmo em todas elas, ou seja: o racismo, essa elaboração fria e extrema do modelo ariano de explicação cuja presença é uma constante em todos os níveis de pensamento, assim com parte e parcela das mais diferentes instituições dessas sociedades. [...] o racismo estabelece uma hierarquia racial e cultural que opõe a "superioridade" branca ocidental à "inferioridade” negroafricana (GONZALEZ, 1988, p. 121).

Convém destacar as rasuras provocadas no cânone literário por Ana Maria Gonçalves e Luz Argentina Chiriboga, visto que elas cumprem uma agência política de inserção de mulheres negras como sujeitas de suas múltiplas histórias e que delineiam narrativas que subvertem hegemonias colonialistas. Além disso, o conceito de escrevivência, cunhado pela escritora e Doutora em Literatura Comparada Conceição Evaristo, abarca as produções literárias destas autorias amefricanas, pois se tratam de escritas que envolvem as experiências de vida de pessoas negras. Evaristo nos explica que:

Escrevivência, em sua concepção inicial, se realiza como um ato de escrita das mulheres negras, como uma ação que pretende borrar, desfazer uma imagem do passado, em que o corpo-voz de mulheres negras escravizadas tinha sua potência de emissão também sob o controle dos escravocratas, homens, mulheres e até crianças. E se ontem nem a voz pertencia às mulheres escravizadas, hoje a letra, a escrita, nos pertencem também. Pertencem, pois nos apropriamos desses signos gráficos, do valor da escrita, sem esquecer a pujança da oralidade de nossas e de nossos ancestrais. Potência de voz, de criação, de engenhosidade que a casa-grande soube escravizar para o deleite de seus filhos. E se a voz de nossas ancestrais tinha rumos e funções demarcadas pela casa-grande, a nossa escrita não. Por isso, afirmo: “a nossa escrevivência não é para adormecer os da casa-grande, e sim acordá-los de seus sonos injustos" (EVARISTO, 2020, p. 11).

Assim, é possível situar estas escritoras em um rol de mulheres negras que expõem, por meio de suas escrevivências, as violências da colonização, o racismo, os mecanismos de sobrevivência e (re) existências e as formas de afetividade de pessoas negras. Segundo Leda Maria Martins: 
É do lócus da ficção e da poesia que a escritora negra, em particular, busca rasurar esses vícios de figuração, vestindo a personagem negra feminina com novos significantes que indiciam outras possibilidades de significância e de interferência nos processos de alçamento do corpo feminino como corpo de linguagem. Traduzindo sua condição binária de mulher e negra, as escritoras afro-brasileiras, em muitas de suas produções, elegem o corpo feminino como tema, do qual derivam a artesania da escrita (MARTINS, 1996, p. 112).

Desta forma, nesta análise, considero que as tessituras literárias de Ana Maria Gonçalves e Luz Argentina Chiriboga, ao personificar, em especial, Kehinde (Um defeito de cor, Brasil, 2006) e Jonatás (Jonatás y Manuela, Equador, 1994) nos conduzem ao (re) encontro com mulheres negras que, inseridas no contexto de escravização, subvertem expectativas e imposições sociais.

Ana Maria Gonçalves (2017) pontua que a literatura é um espaço de possibilidades e, por meio das duas identidades complementares, mulher e negra, sua escrita é consolidada. Segundo ela, "é a partir desses dois lugares que experimento o mundo, e é também neles que busco as histórias que me interessa contar, esperando que não sejam lugares limitadores, mas de inclusão e colaboração com o projeto de narrativa da experiência humana".

O romance Um defeito de cor ganhou forma a partir da mudança de Ana Maria Gonçalves de São Paulo para a Bahia e de pesquisas historiográficas. A escritora revela que a obra:

nasceu da minha vontade de entender melhor o que foi a Revolução Malê, tão importante quanto curiosa, pois se trata de uma rebelião coordenada por escravos mulçumanos em plena Bahia, em 1835, e da qual passei todo o meu período escolar sem ter tomado conhecimento. Acredito que um interesse maior sobre esse assunto tenha surgido depois da invasão do Iraque, mas antes era mais conhecida apenas na Bahia e por estudiosos da história colonial e africanistas. Depois, quando ouvi falar de Luísa Mahin, o romance tomou outro rumo e a Revolução Malê acabou se concentrando mais em apenas um dos dez capítulos (GONÇALVES, 2018).

Similarmente à Ana Maria Gonçalves, Luz Argentina Chiriboga tece palavras que encontram suas experiências de vida, assim como as do povo negro e transcende os limites geográficos e temporais. Por meio de suas narrativas, Chiriboga apresenta personagens, espaços, tramas e outros aspectos que problematizam a dominância e as violências coloniais e exalta o protagonismo das/ os negras/os na luta pela liberdade e na exaltação das raízes negro-africanas no Equador. Conforme Chiriboga: 
Mi obra es una toma de consciencia histórica y social de negritud, vibra con mitos, leyendas, canciones, danzas, y enlaza con ternura el pasado con el presente. En el Ecuador no se ha superado del todo aquel sentimiento soterrado de odio contra las personas que están fuera del conglomerado blanco, porque las encuentran diferentes y débiles. Para justificar su sentimiento lo disfrazan atribuyéndoles defectos: crueldad, ociosidad, resentimiento, atraso, traición, etc. Los programas de educación impartidos en los jardines de infantes, escuelas y colegios no enseñan los valores de la cultura afroecuatoriana, y lo que no se conoce no se ama (CHIRIBOGA, 2000, p. 274).

O romance Um defeito de cor ganhou forma a partir da mudança de Ana Maria Gonçalves de São Paulo para a Bahia e de pesquisas historiográficas. A escritora revela que a obra:

nasceu da minha vontade de entender melhor o que foi a Revolução Malê, tão importante quanto curiosa, pois se trata de uma rebelião coordenada por escravos mulçumanos em plena Bahia, em 1835, e da qual passei todo o meu período escolar sem ter tomado conhecimento. Acredito que um interesse maior sobre esse assunto tenha surgido depois da invasão do Iraque, mas antes era mais conhecida apenas na Bahia e por estudiosos da história colonial e africanistas. Depois, quando ouvi falar de Luísa Mahin, o romance tomou outro rumo e a Revolução Malê acabou se concentrando mais em apenas um dos dez capítulos (GONÇALVES, 2018).

Assim, tais criações literárias acordam com as estratégias do fazer literário inserido em espaços de segregação e violência apontadas por Deleuze e Guattari (1977, p. 26-27) em que "o caso individual é imediatamente ligado à política" e, desta forma, "tudo nela adquire um valor coletivo". Acredito, pelo olhar e a leitura das obras supracitadas de Ana Maria Gonçalves e Luz Argentina Chiriboga, bem como suas trajetórias enquanto ser-estar mulheres negras em espaços que foram colonizados e que ainda carregam marcas da colonialidade.

Sendo assim, é possível enunciar que escritoras como Ana Maria Gonçalves e Luz Argentina Chiriboga rasuram imposições de tais categorias dicotômicas, rompendo fronteiras do ser-existir negro por meio de textos-tecidos. Em relação à produção e notoriedade de Chiriboga, Sandra Carbajal pontua que:

[...] Chiriboga sería el equivalente a la escritora Conceição Evaristo de Brasil. Ella estuvo nominada a tener un puesto en la Academia Brasileña de Letras (ABL) en el 2018, pero se lo negaron. Argentina sería una figura parecida, debido a la similitud en perspectiva que desarrolla sobre el protagonismo del rol constructor y transformador de las mujeres en general, no solo de las afrodescendientes. Se debería situar a Luz Argentina en el campo de la literatura en general y dejar de encasillarla en la denominada literatura afro. Su 
impacto tiene que ver con reconstruir y reformular una narrativa de la historiografía, específicamente de la independencia y de los fundamentos del republicanismo en América Latina y el Caribe (CARBAJAL, 2020, p. 119).

As duas obras apontam para a colonização nas Américas e os efeitos da migração forçada, que não são lineares. Entre estes, estão o desgarramento do território de origem, o direito negado à história ancestral e aos laços familiares. A subtração do nome, como forma de negação colonial à condição humana de africanas e africanos, e a imposição de um nome cristão configurou e simbolizou esta dinâmica e foi apontada em ambas as obras. São exemplos do diálogo e das confluências entre as duas narrativas os excertos a seguir. Em Jonatás y Manuela, a narradora conta:

Reiteró la ceremonia en cada una de las prisioneras. Nasakó, al tocarle su turno, lloró y fue bautizada con el nombre de Juana Carabalí. Mina fue Carmen Taté. Fueron advertidas que serían castigadas en caso de continuar usando sus nombres anteriores. El hombre blanco, dueño de cañaverales, les había robado lo último que les quedaba, sus nombres (CHIRIBOGA, 1994, p. 37).

Já em Um defeito de cor:

Foi então que ficamos sabendo o motivo da demora no embarque dos homens, pois os brancos tinham batizado todos eles com nomes que chamavam de nomes cristãos, nomes de brancos, e àquele homem da perna machucada, de acordo com um outro que estava logo atrás dele na fila, tinham dado o nome de João. Soubemos que o padre que fez os batizados tinha chegado atrasado, depois do embarque das mulheres. Os guardas colocaram os homens em fila e, um por um, tiveram que dizer o nome africano, o que podia ser revelado, é claro, e o lugar onde tinham nascido, que eram anotados em um livro onde também acrescentavam um nome de branco. Era esse nome que eles tinham que falar para o padre, que então jogava água sobre suas cabeças e pronunciava algumas palavras que ninguém entendia. Sabiam apenas que era com tal nome que teriam que se apresentar no estrangeiro (GONÇALVES, 2017, p. 49).

No contrafluxo do sistema colonial, as protagonistas, criadas por Gonçalves e Chiriboga, forjam espaços e se mantêm conectadas à identidade ancestral. Na narrativa de Gonçalves (2017, p. 73): "Para os brancos fiquei sendo Luísa, Luísa Gama, mas sempre me considerei Kehinde. O nome que a minha mãe e a minha avó me deram e que era reconhecido pelos voduns, por Nana, por Xangô, por Oxum, pelos Ibêjis e principalmente pela Taiwo.” E em Chiriboga (1994, p. 76): "Ella grabó su apellido en el recuerdo de los que en la travesía lo perdieron, de los guindados en los mástiles." Nas duas obras, as 
mulheres negras são sujeitas de suas ações e, como agentes incumbem-se das reflexões, dos pensamentos, dos saberes e fazeres que não são individuais, e, sim, transversais à coletividade.

Outro aspecto interessante de atentar em ambas as obras são os pontos que se assemelham quanto às representações e reconhecimentos dos corpos negros, sobretudo das mulheres negras. Kehinde e Jonatás - inseridas em um regime escravocrata perverso, que aniquilou as imagens, e o reconhecimento destas, de negras e negros deixando marcas que ainda hoje sentidas nestes corpos - ao depararem-se com o seu reflexo no espelho, decerta forma aparentam resistência quanto a estes reconhecimentos.

No caso de Kehinde, por exemplo, ela acreditara que sua imagem era semelhante à da sinhazinha. A sua entrada na casa grande representa uma série de (re)encontros.

\begin{abstract}
A Esméria parou na frente dele [o espelho] e me chamou, disse para eu fechar os olhos e imaginar como eu era, com o que me parecia, e depois podia abrir os olhos e o espelho me diria se o que eu tinha imaginado era verdade ou mentira. Eu sabia que tinha a pele escura e o cabelo duro e escuro, mas me imaginava parecida com a sinhazinha (GONÇALVES, 2017, p. 85).
\end{abstract}

O espelho para este corpo, ao contrário do que a mente colonizadora poderia intentar, é um presente, já que os reflexos de Kehinde e de Jonatás transmutam-se em reflexão-ação-autoconsciência. Em "Um defeito de cor":

Olhando no espelho, eu me achei linda, a menina mais linda do mundo, prometi que um dia ainda seria forra e teria, além das roupas iguais às das pretas do mercado, muitas outras iguais às da sinhazinha. Ela também deve ter me achado bonita e ficado com ciúme, pois logo deu a brincadeira por terminada e pediu que eu tirasse tudo antes que estragasse, ou antes que a sinhá Ana Felipa aparecesse e brigasse com nós duas (GONÇALVES, 2017, p. 87).

Em "Jonatás y Manuela”:

Le invadió una ráfaga de angustia, pero algo que le andaba por las venas y no podía apartarlo, le afloró de pronto. Clavó los ojos en sus ojos, los vio brillantes, expresivos, gozosos; sonrió, el espejo retrató sus dientes blancos; ah, aquellas trenzas terminadas en canutos de colores la volvían atractiva; no, no soy tan fea. Al despedirse del espejo, llevó la convicción de que era bonita, que Changó sea contigo, musitó y fue a golpear el dormitorio de sus amas (CHIRIBOGA, 1994, p. 93).

Refletir sobre as imagens e as (re) significações do corpo negro de Kehinde e de Jonatás perpassam também pela representação do espelho, abebé, 
de Oxum, que reflete o poder. O espelho não serve apenas para se enxergar, ele simboliza um instrumento para as guerras travadas e vencidas ao longo das trajetórias das duas personagens. Nos recortes supracitados, é possível ver conciliações das referências de beleza. Ana Maria Gonçalves e Luz Argentina Chiriboga proporcionam, a leitoras e leitores, (re) encontros com mulheres negras que, inseridas no contexto de escravização, subvertem expectativas e imposições sociais. O olhar para o espelho de Oxum e para o espelho de Kehinde e de Jonatás reconstitui minha imagem, minha identidade. As afrografias e as vozes das personagens de Ana Maria Gonçalves e Luz Argentina Chiriboga são sopros ancestrais que rompem o silenciamento de séculos. E é nítido que, ao rasurar espaços tidos como hegemônicos, causam desconforto e tendem a seculares tentativas de apagamento, visto o medo o qual sinaliza a escritora e psicóloga Grada Kilomba:

Existe um medo apreensivo de que, se o(a) colonizado(a) falar, o(a) colonizador(a) terá que ouvir e seria forçado(a) a entrar em uma confrontação desconfortável com as verdades do 'Outro'. Verdades que têm sido negadas, reprimidas e mantidas guardadas, como segredos. Eu realmente gosto desta frase "quieto como é mantido" . Esta é uma expressão oriunda da diáspora africana que anuncia o momento em que alguém está prestes a revelar o que se presume ser um segredo. Segredos como a escravidão. Segredos como o colonialismo. Segredos como o racismo (KILOMBA, 2016).

Em seus movimentos contracoloniais, Gonçalves e Chiriboga cumprem, desde um olhar de dentro e em desacordo com as omissões estabelecidas por uma sociedade patriarcal e racista, o papel da inscrição e da escrita de história de negras e negros em África e nas Américas. Portanto, mesmo que produções literárias afrodiaspóricas diferenciem-se, levando em conta subjetividades, trajetórias e contextos socioculturais-históricos distintos, existem confluências nas experiências de ser mulher negra no Brasil, no Equador, na Améfrica Ladina. Estas escritas são, para mim, a mostra de caminhos e reflexos de mulheres que ressurgem apontando a força da ancestralidade e que, vivas em meu corpo-memória-documento, tonificam para embates presentes e futuros em epistemologias e ações políticas de [auto] afirmação e reconhecimento de corpos negros.

A reflexão e a compreensão destas escritas são possíveis também a partir da leitura do texto "Falando em línguas: uma carta para as mulheres escritoras do terceiro mundo", em que a intelectual chicana Gloria Anzaldúa salienta:

Por que sou levada a escrever? Porque a escrita me salva da complacência que me amedronta. Porque não tenho escolha. Porque devo manter vivo o espírito de minha revolta e a mim mesma também. Porque o mundo que crio na escrito compensa o que 
o mundo real não me dá. No escrever coloco ordem no mundo, coloco nele uma alça para poder segurá-lo. Escrevo porque a vida não aplaca meus apetites e minha fome. Escrevo para registrar o que os outros apagam quando falo, para reescrever as histórias mal escritas sobre mim, sobre você. Para me tornar mais íntima comigo mesma e consigo. Para me descobrir, preservar-me, construir-me, alcançar autonomia. (ANZALDÚA, 2000, p. 229)

Desta maneira, estabelecer contatos entre as escrevivências de mulheres negras em diferentes países - neste caso, Brasil e Equador -, com suas especificidades, favorece uma aproximação da experiência de colonização na América Latina e se configura como oportunidade de visibilidade a um movimento de mulheres negras descolonizado com o intuito de restituir memórias. Dialogar com o tempo, estreitar os laços com a memória ancestral, reencontrar possíveis caminhos a partir das palavras daquelas que vieram antes de nós. Estas ações conduzem de distintas e potentes formas a recepção de escritos literários de/ para mulheres negras, além de amenizar um pouco a nossa saudade ancestral por meio destes encontros.

Analisar as obras Um defeito de cor e Jonatás y Manuela configura-se também em explorar as estratégias sagazes da escritora de denúncia, à época, ao regime escravagista permeado pelo discurso branco-colonial-hegemônico, além de expressar o encontro com a memória coletiva de ser negra/o. Estas leituras nos conduzem à compreensão do corpo enquanto memória, existência e pertencimento, trata-se, portanto, de, por meio de reconstrução histórica, relacionar narrativas de passado e de presente. As personagens Kehinde e Jonatás, sob este prisma, podem ser lidas como personificações da encruzilhada de vivências e dos trânsitos que são causa e consequência de ser mulher negra na Améfrica.

\section{Referências}

ANZALDÚA, Gloria. Falando em línguas: uma carta para as mulheres escritoras do terceiro mundo. Revista Estudos Feministas, v. 8, n. 1, p. 229-236, 2000.

BARR, Shirley Campbell. Letras e vozes da diáspora negra. In: FERNANDES, Jaqueline; PINTO, Ana Flávia Magalhães, DECHEN, Chaia (orgs.). Griôs da diáspora negra. Brasilia: Griô, 2017, p. 21-31.

CARBAJAL, Sandra. Literatura, raza y género: tres entrevistas a la Luz de la obra de Argentina Chiriboga. Textos y Contextos (segunda época), [S. 1.], v. 1, n. 21, p. 109 - 122, 2020a. Disponível em: <https://revistadigital.uce.edu.ec/index.php/CONTEXTOS/article/view/2508> . Acesso em: 30 mar. 2021.

CHIRIBOGA, Luz Argentina. Jonatás y Manuela. Quito: Editorial Casa de la Cultura Ecuatoriana, 1994. 
CHIRIBOGA, Luz Argentina. Narradoras ecuatorianas de hoy. Una antología crítica. Puerto Rico: Editorial de la Universidad de Puerto Rico, 2000.

COLLINS, Patricia Hill. Pensamento feminista negro: conhecimento, consciência e a política do empoderamento. Boitempo Editorial, 2019.

EVARISTO, Conceição. Sobre o que nos move, sobre a vida In: DUARTE, Constância Lima; NUNES, Isabella Rosado (org.) Escrevivência: a escrita de nós: reflexões sobre a obra de Conceição Evaristo. Rio de Janeiro: Mina Comunicação e Arte, 2020.

GONÇALVES, Ana Maria. Um defeito de cor. 15 ed. Rio de Janeiro: Record,2017

GONZALEZ, Lélia A categoria político-cultural de amefricanidade (1988). In: GONZALEZ, Lélia: Primavera para as rosas negras. Diáspora Africana: Ed. Filhos da África, 2018.

KILOMBA, Grada. Descolonizando o conhecimento. Palestra-performance. São Paulo: Centro Cultural São Paulo, 2016. Disponível em: < https://mitsp. org/2016/portfolio/descolonizando-o-conhecimento-uma-palestra-performance-de-grada-kilomba/> Acesso em: 25 mar. 2021.

MARTINS, Leda Maria. O Feminino corpo da negrura. Aletria: Revista de Estudos de Literatura, [S. 1.], v. 4, p. 111-121, 1996. DOI: 10.17851/2317-2096.4.111-121. Disponível em: https://periodicos.ufmg.br/index.php/aletria/article/view/17706. Acesso em: 10 set. 2021.

MARTINS, Leda Maria. Afrografias da Memória: o reinado do rosário do jatobá. São Paulo: Perspectiva, 1997.

NASCIMENTO, Maria Beatriz. O conceito de quilombo e a resistência cultural negra (1985). In: RATTS, Alex. Eu sou Atlântica: sobre a trajetória de vida de Beatriz Nascimento. São Paulo: Instituto Kuanza, 2007. 